\title{
Synthesis of [60]Fullerene Adducts Bearing Carbazole Moieties by Bingel Reaction and Their Properties
}

Yosuke Nakamura, Masato Suzuki, Yumi Imai, and Jun Nishimura*

Department of Nano-Material Systems, Graduate School of Engineering,, Gunma University, Tenjin-cho, Kiryu, Gunma 376-8515, Japan

nisimura@chem.gunma-u.ac.jp

\section{Supporting information}

\section{Contents}

1) ${ }^{1} \mathrm{H}$ NMR spectrum of $\mathbf{4}$ in $\mathrm{CDCl}_{3}$.

2) ${ }^{13} \mathrm{C}$ NMR spectrum of 4 in $\mathrm{CDCl}_{3}$.

3) UV-Vis spectrum of $\mathbf{4}$ in toluene.

4) ${ }^{1} \mathrm{H}$ NMR spectrum of $\mathbf{5}$ in $\mathrm{CDCl}_{3}$.

5) ${ }^{13} \mathrm{C}$ NMR spectrum of 5 in $\mathrm{CDCl}_{3}$.

6) UV-Vis spectrum of $\mathbf{5}$ in toluene.

7) ${ }^{1} \mathrm{H}$ NMR spectrum of 7 in $\mathrm{CDCl}_{3}$.

8) ${ }^{13} \mathrm{C}$ NMR spectrum of 7 in $\mathrm{CDCl}_{3}$.

9) UV-Vis spectrum of 7 in toluene. 


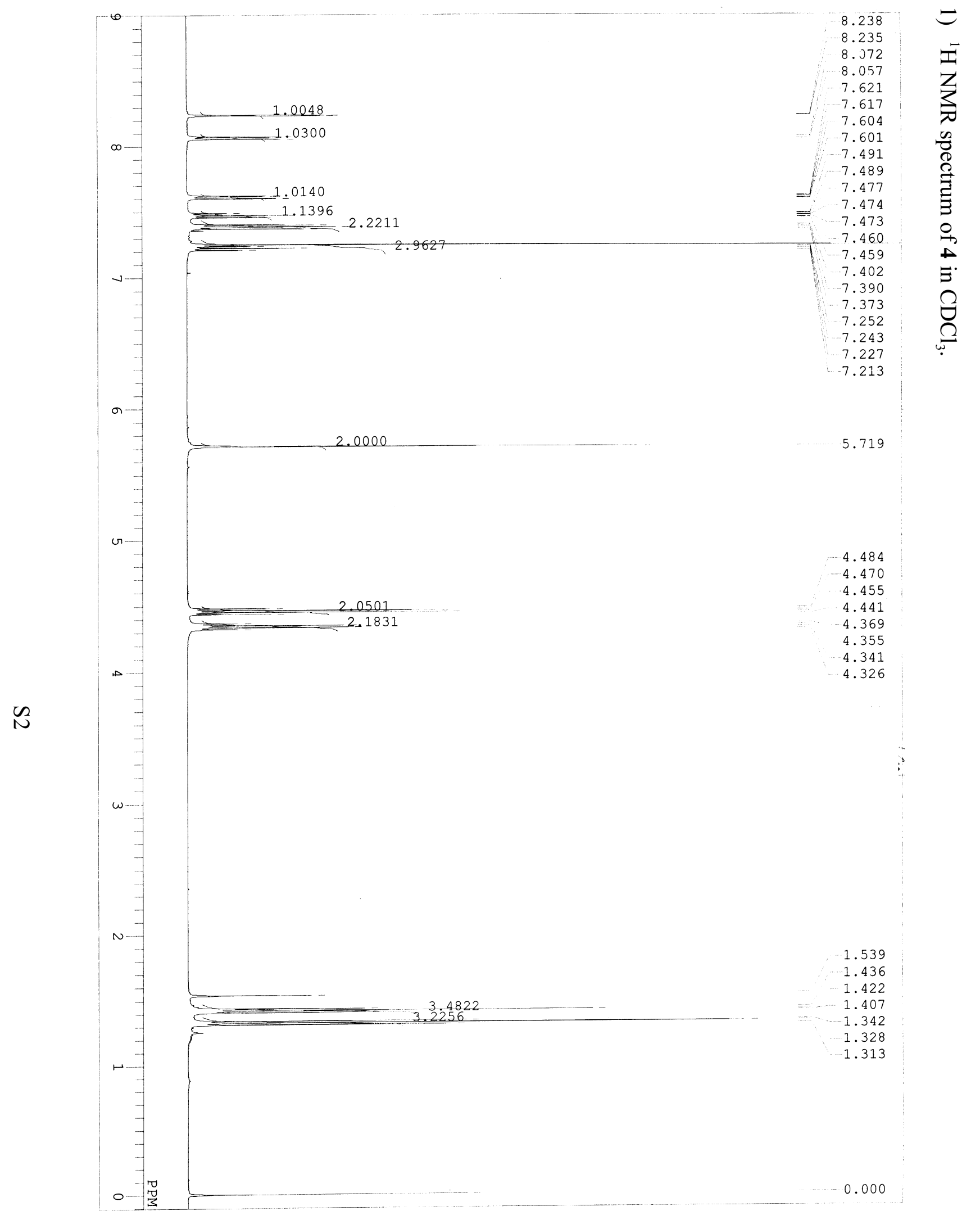




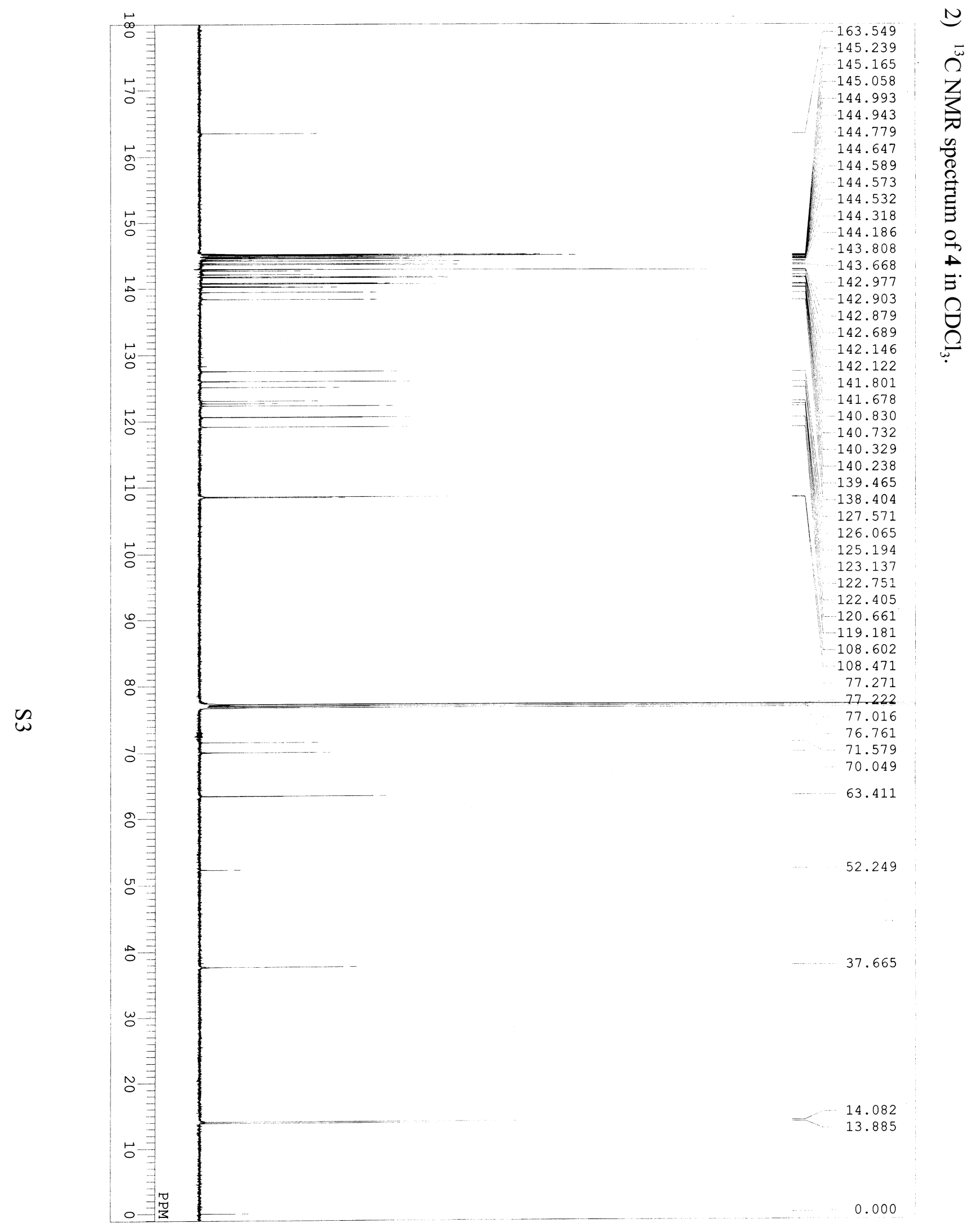




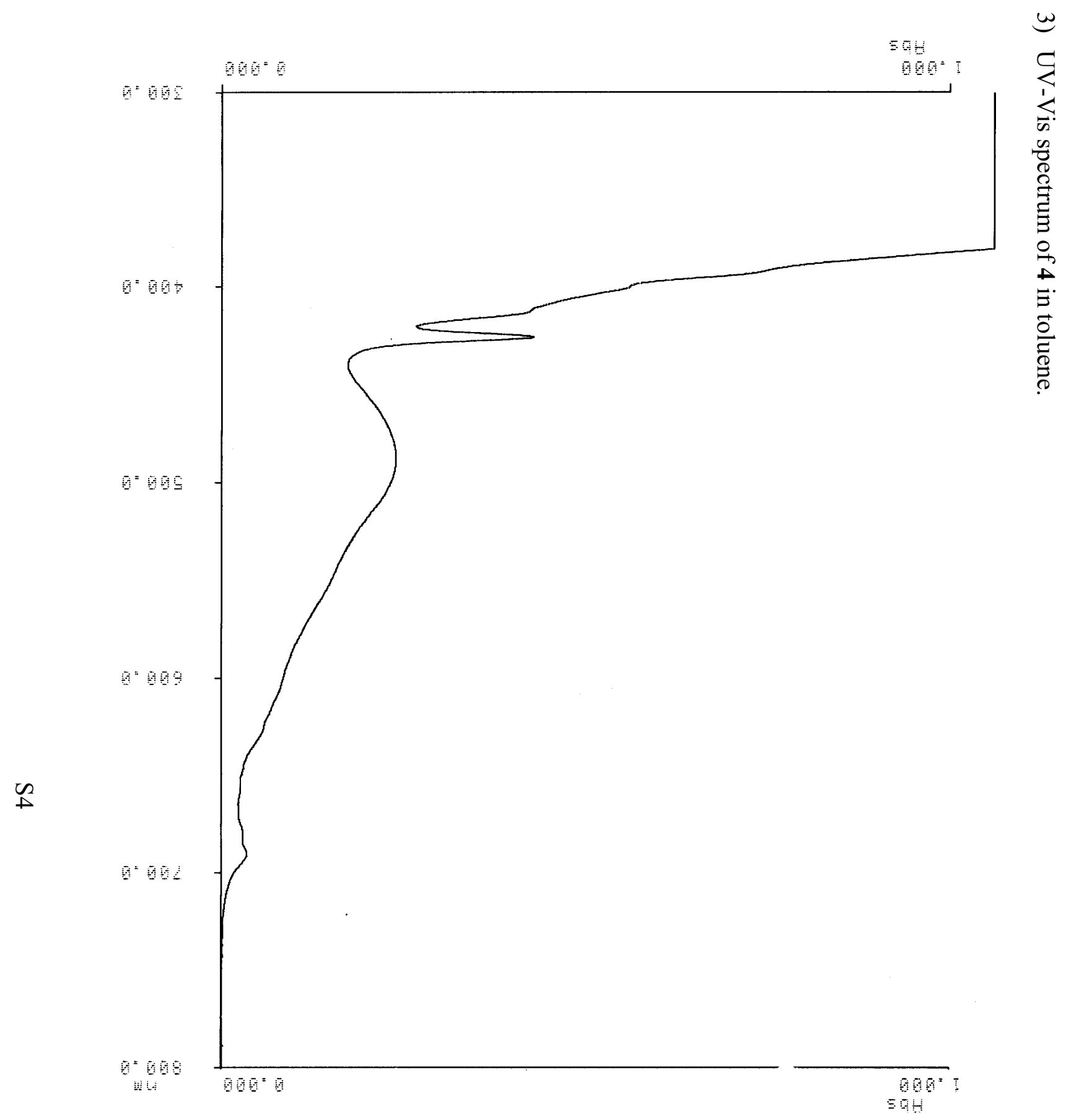




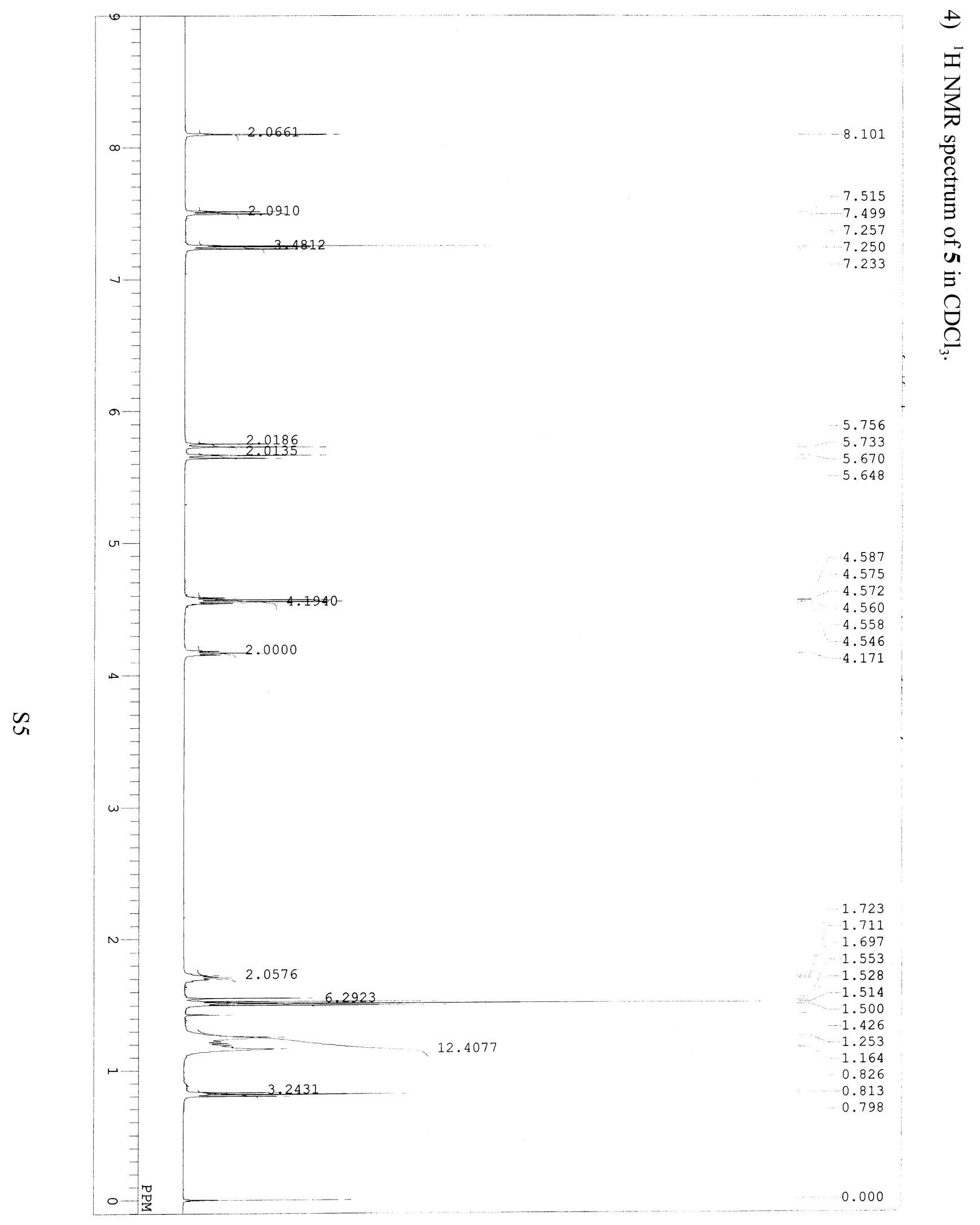




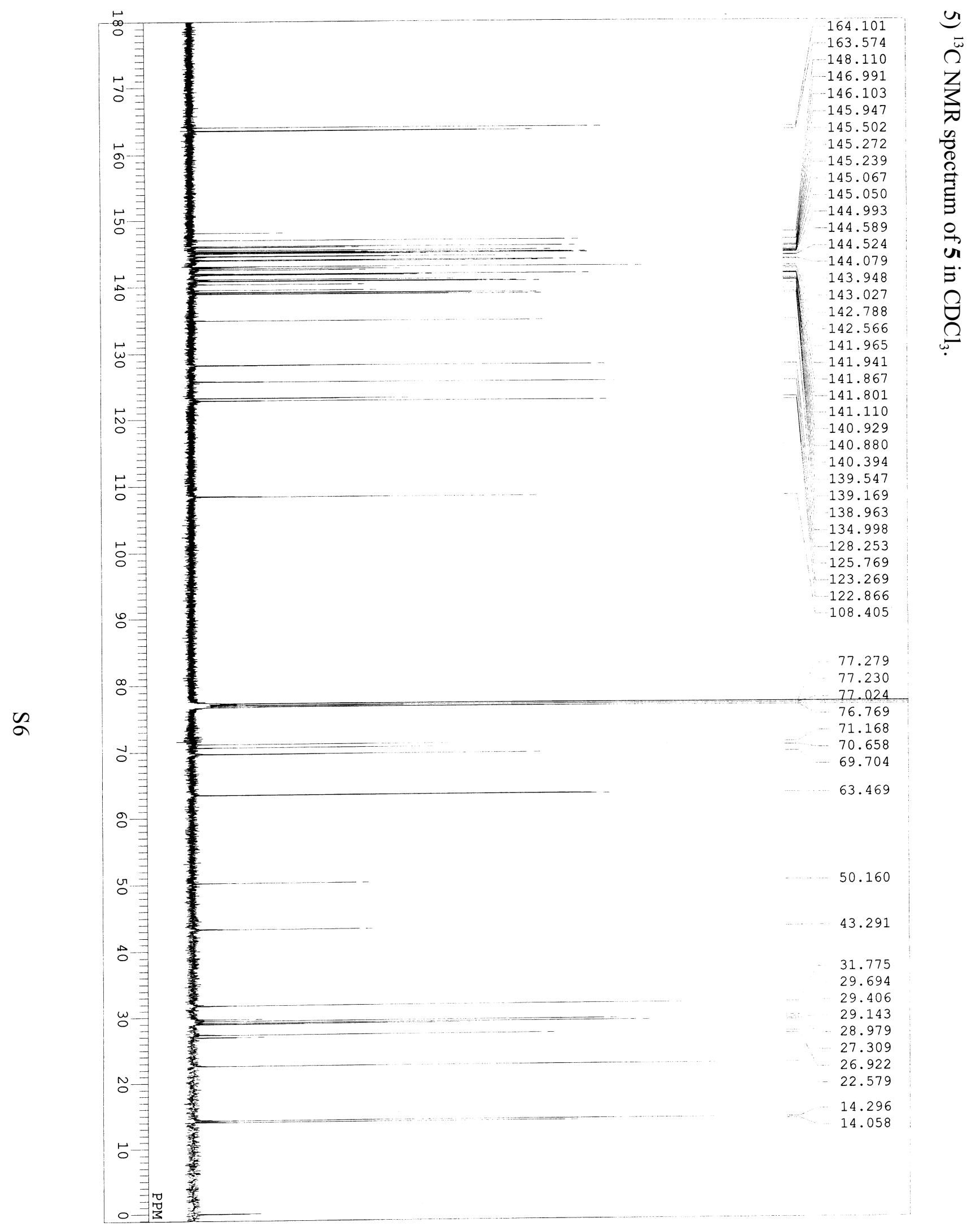




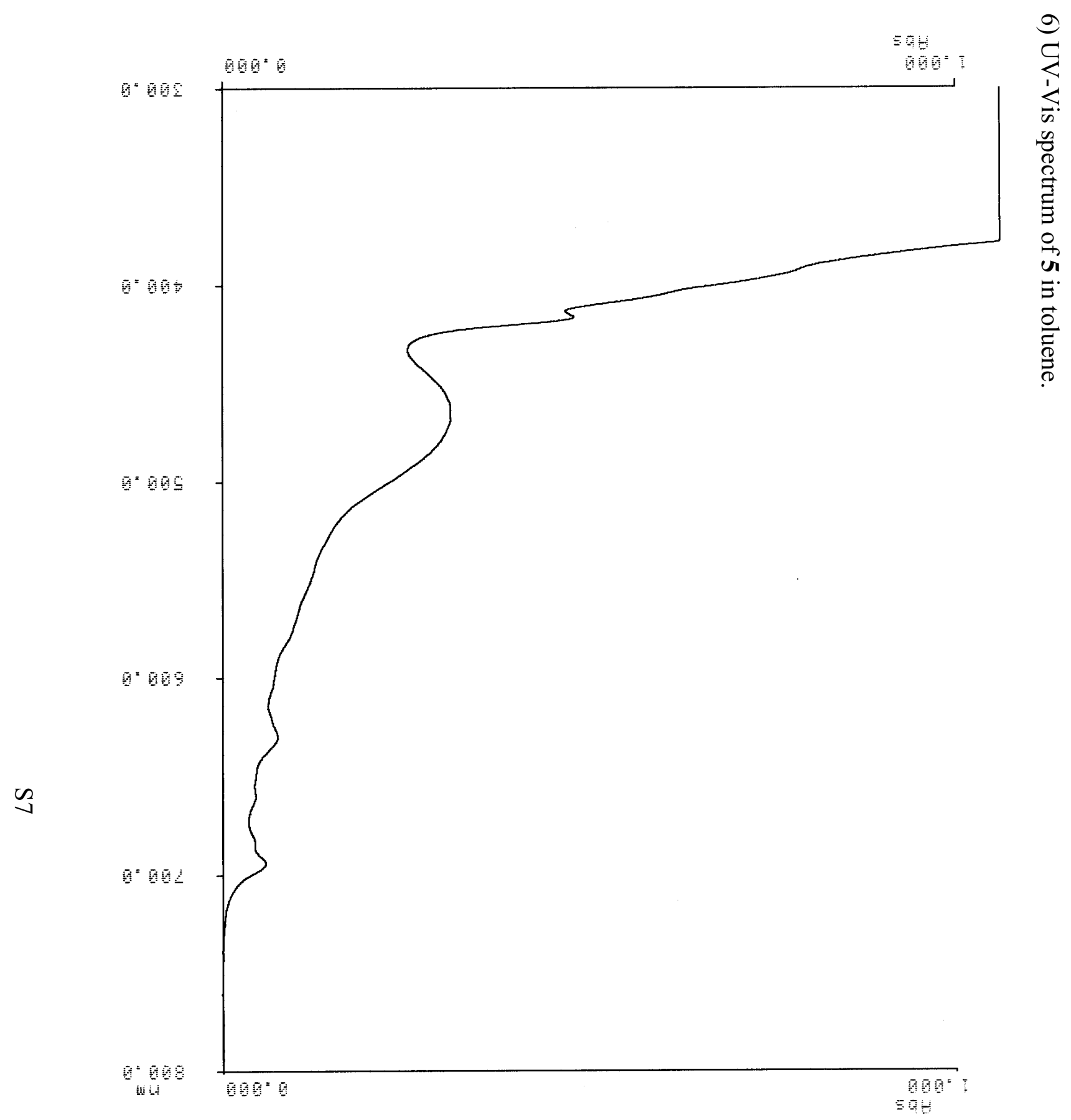




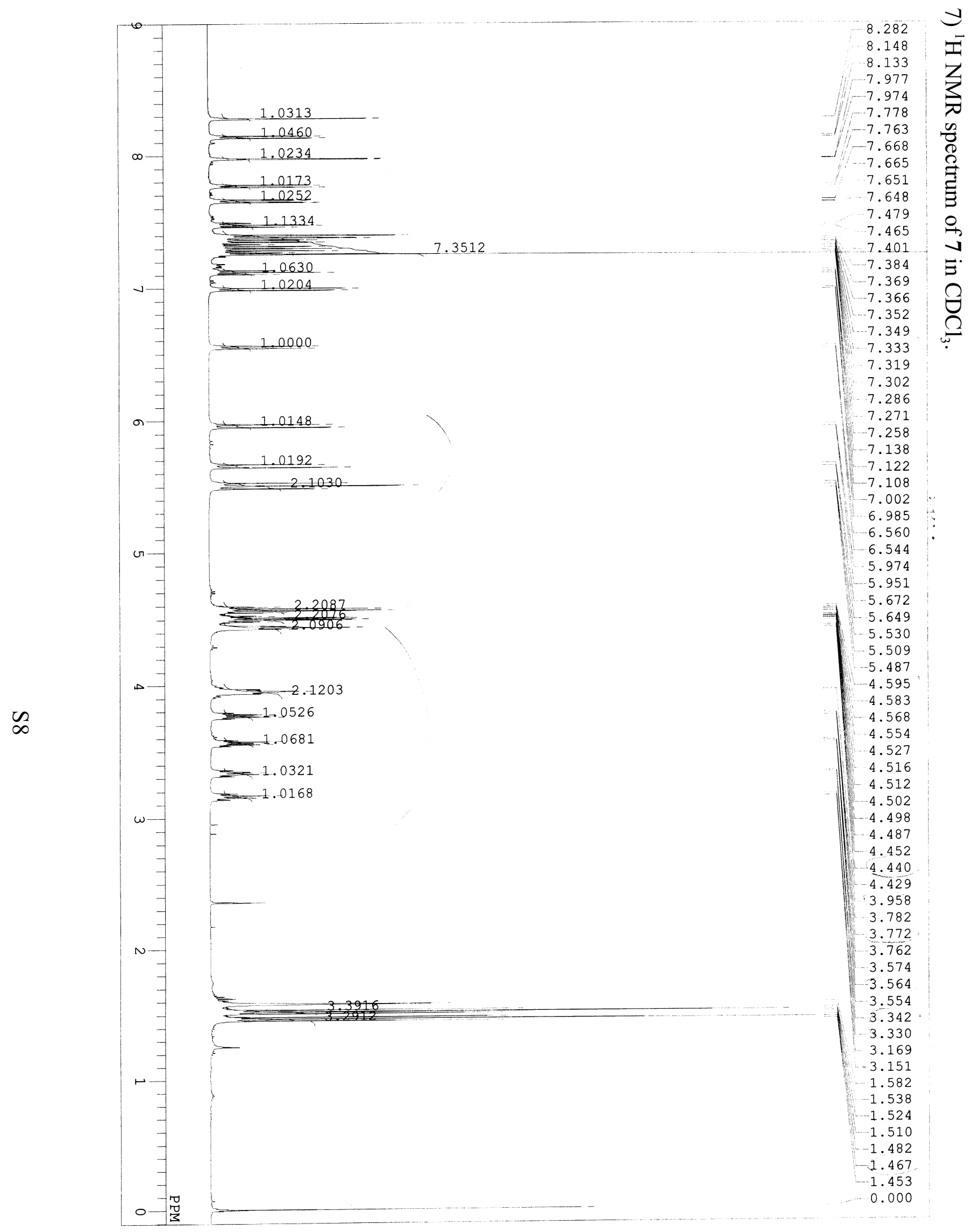




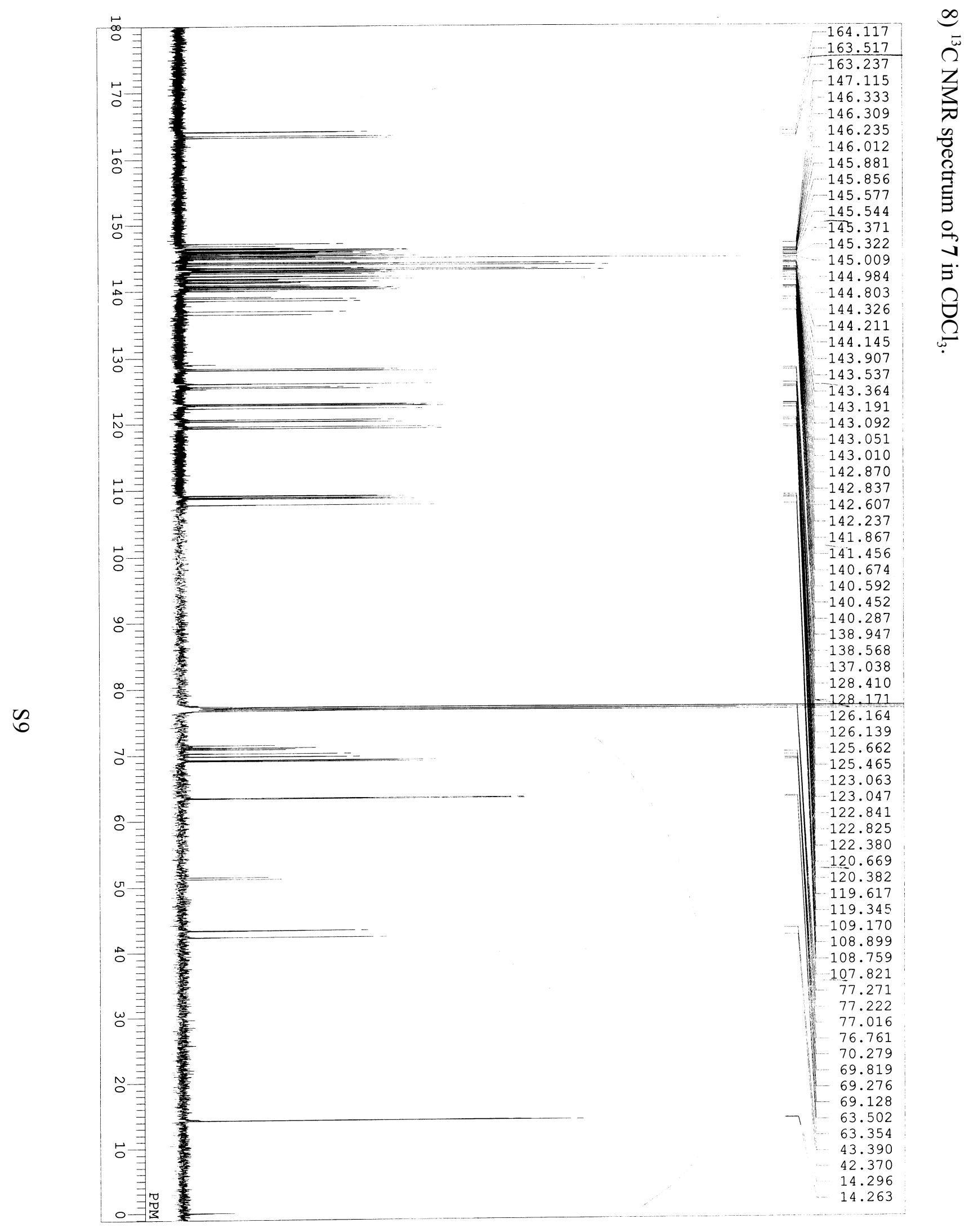




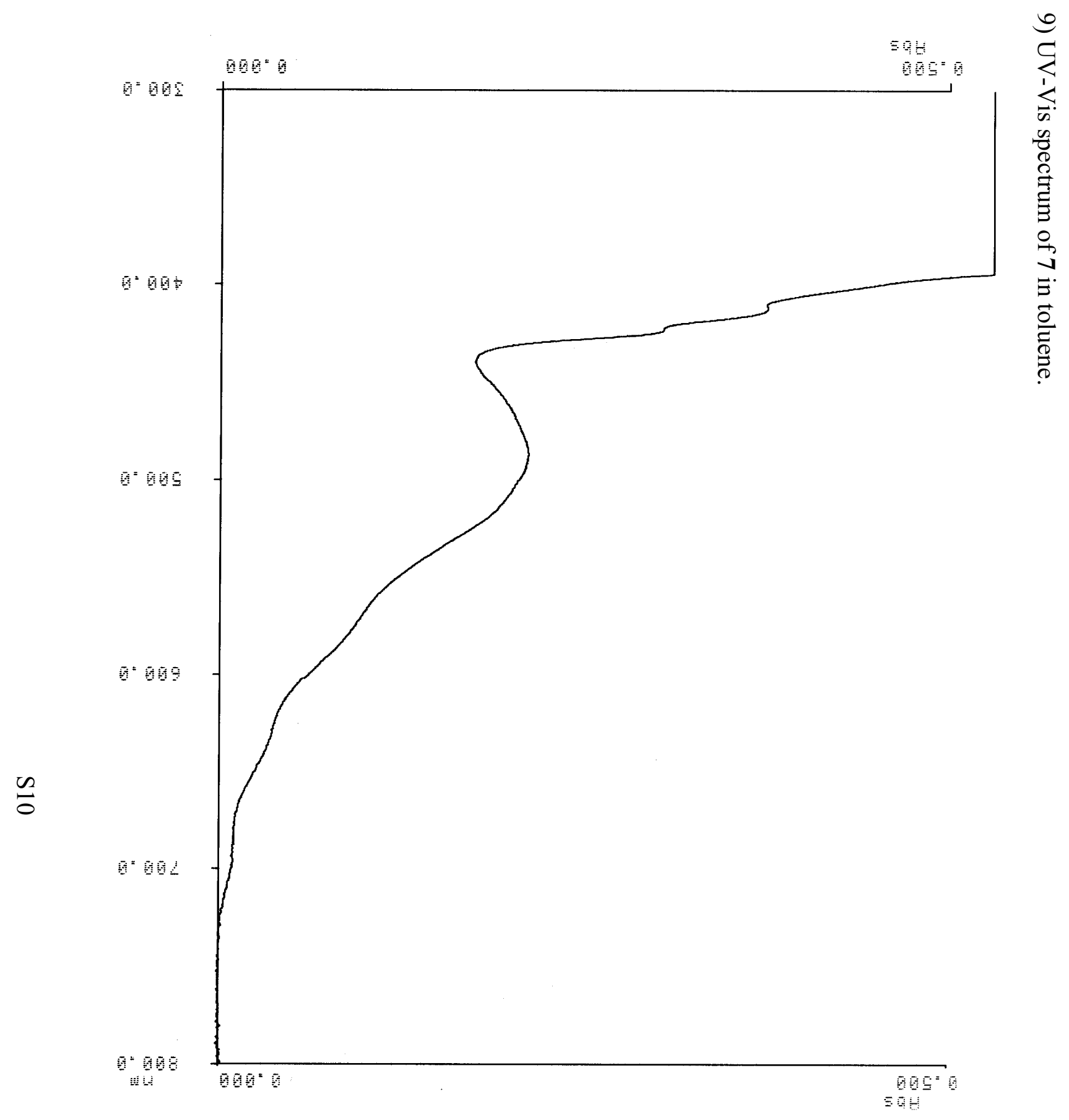

